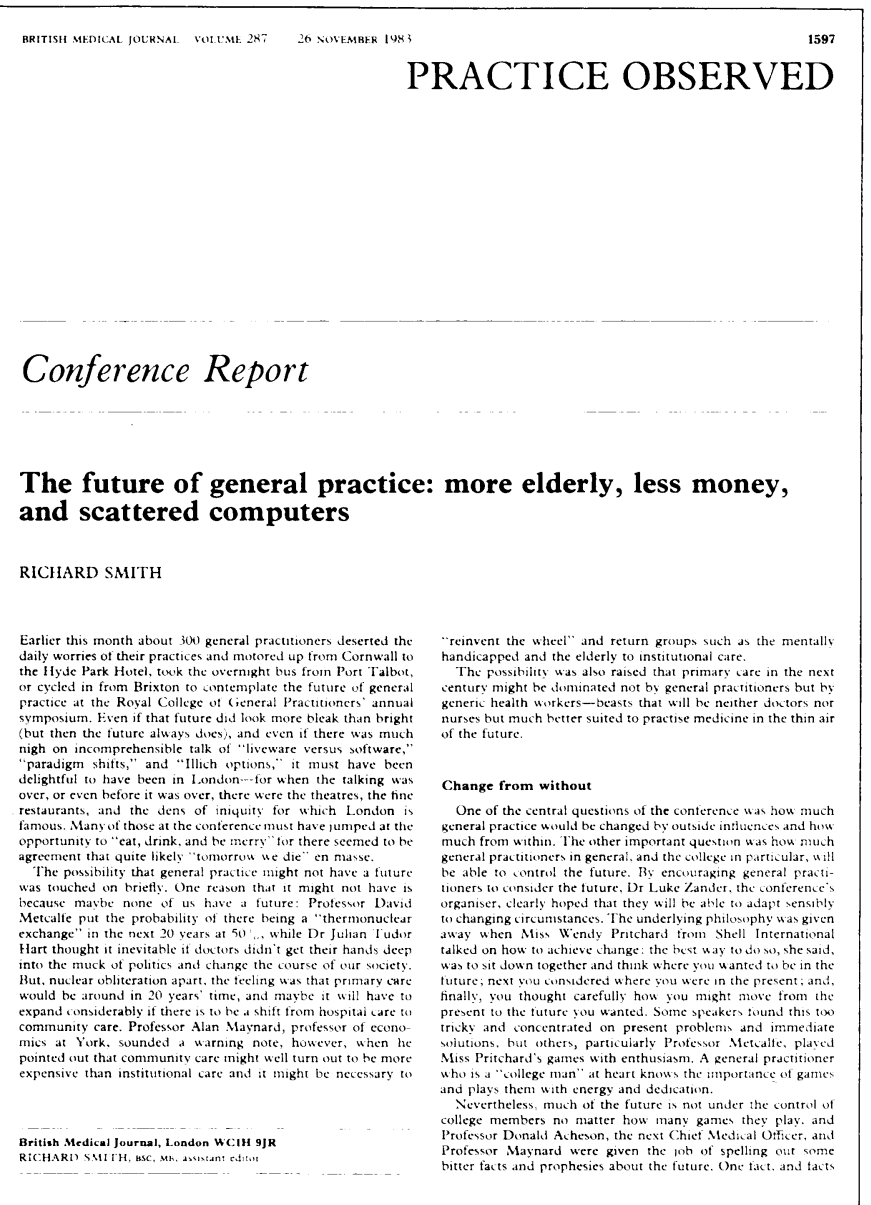

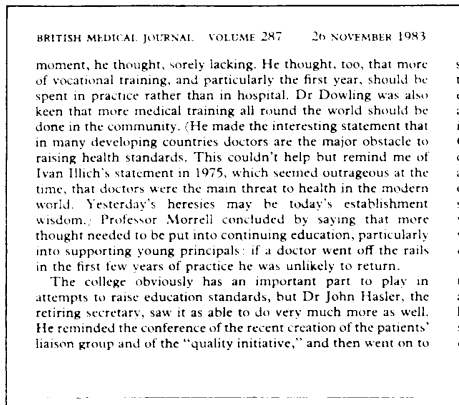

Abstract

An automatic device for measuring blod pressure was
used to scereen all patients a a ged 30 to 055 years registered at a health centre. Of those who were cligibite, $55 \%$ attended. non-attenders. High readings obtained on the automatic
device possibly deterred some patients from reattending
for follow up

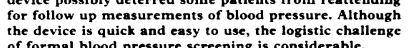

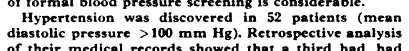

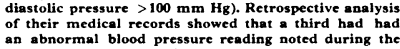

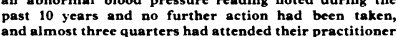
and almost hree quarters had actended heir practitioner
during the previous scar without having a blod pressure
measurement recorded. One year affer the screening proceddure two fifths of the nemly discovered hypertensiviv
patients had defaulted from follow up and treatment.

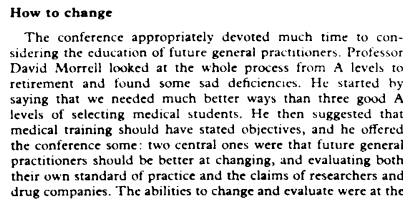

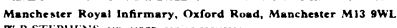

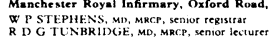

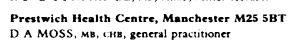

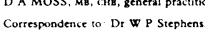

What Annoys Me Most

\section{The telephone}

OL.IVER SAMUEE.

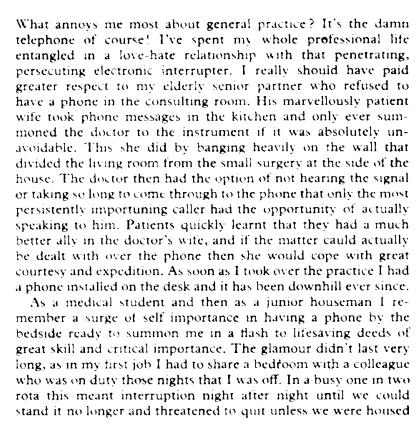

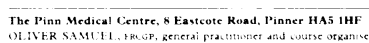

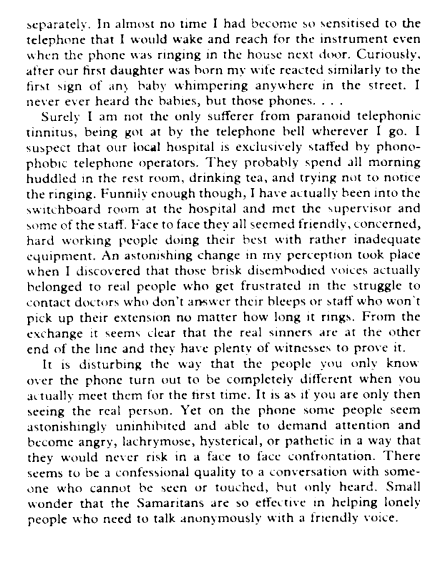

1600

Relentessly pursued

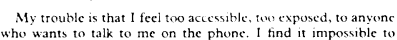

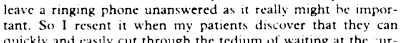

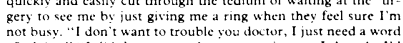

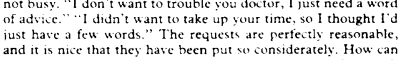

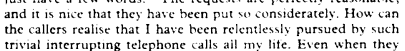

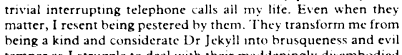

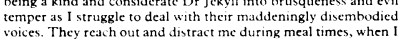

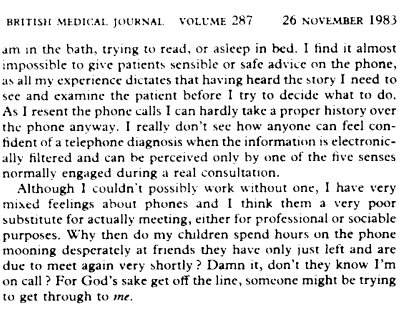

Practice Research

Evaluation of screening for hypertension in general practice with an automatic machine

W P STEPHENS, R D G TUNBRIDGE, D A MOSS

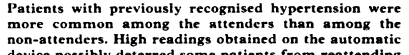

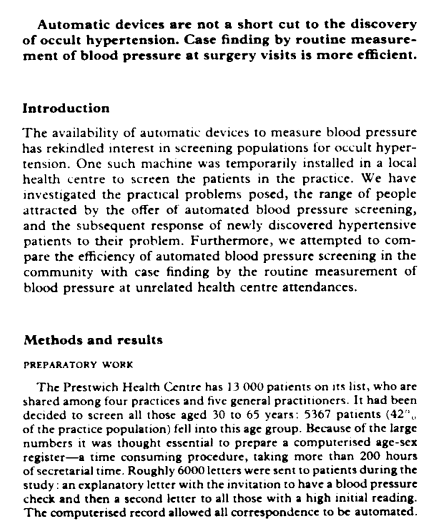

